\title{
Strength of interference screw fixation of meniscus prosthesis matches native meniscus attachments
}

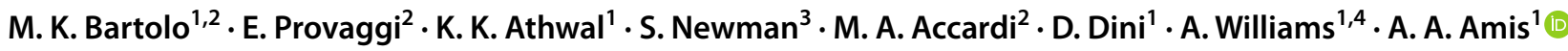

Received: 7 August 2021 / Accepted: 7 October 2021 / Published online: 19 October 2021

(c) The Author(s) 2021

\begin{abstract}
Purpose Meniscal surgery is one of the most common orthopaedic surgical interventions. Total meniscus replacements have been proposed as a solution for patients with irreparable meniscal injuries. Reliable fixation is crucial for the success and functionality of such implants. The aim of this study was to characterise an interference screw fixation system developed for a novel fibre-matrix-reinforced synthetic total meniscus replacement in an ovine cadaveric model.

Methods Textile straps were tested in tension to failure $(n=15)$ and in cyclic tension $(70-220 \mathrm{~N})$ for 1000 cycles $(n=5)$. The textile strap-interference screw fixation system was tested in $4.5 \mathrm{~mm}$-diameter single anterior and double posterior tunnels in North of England Mule ovine tibias aged $>2$ years using titanium alloy (Ti6Al4Va) and polyether-ether-ketone (PEEK) screws $(n \geq 5)$. Straps were preconditioned, dynamically loaded for 1000 cycles in tension (70-220 N), the fixation slippage under cyclic loading was measured, and then pulled to failure.

Results Strap stiffness was at least 12 times that recorded for human meniscal roots. Strap creep strain at the maximum load $(220 \mathrm{~N})$ was 0.005 following 1000 cycles. For all tunnels, pull-out failure resulted from textile strap slippage or bone fracture rather than strap rupture, which demonstrated that the textile strap was comparatively stronger than the interference screw fixation system. Pull-out load (anterior $544 \pm 119 \mathrm{~N}$; posterior $889 \pm 157 \mathrm{~N}$ ) was comparable to human meniscal root strength. Fixation slippage was within the acceptable range for anterior cruciate ligament graft reconstruction (anterior $1.9 \pm 0.7 \mathrm{~mm}$; posterior $1.9 \pm 0.5 \mathrm{~mm}$ ).

Conclusion These findings show that the textile attachment-interference screw fixation system provides reliable fixation for a novel ovine meniscus implant, supporting progression to in vivo testing. This research provides a baseline for future development of novel human meniscus replacements, in relation to attachment design and fixation methods. The data suggest that surgical techniques familiar from ligament reconstruction may be used for the fixation of clinical meniscal prostheses.
\end{abstract}

Keywords Knee $\cdot$ Meniscus $\cdot$ Fixation system $\cdot$ Meniscus replacement $\cdot$ Ovine $\cdot$ Pull-out strength $\cdot$ Slippage $\cdot$ Interference screws $\cdot$ Tensile $\cdot$ Creep

\section{Abbreviations}

ACL Anterior cruciate ligament

AL Antero-lateral

AM Antero-medial

IS Interference screw

\section{A. A. Amis}

a.amis@imperial.ac.uk

1 Biomechanics Group, Mechanical Engineering Department, Imperial College London, London SW7 2AZ, UK

2 Orthonika Ltd, London, UK

3 Department of Surgery and Cancer, Imperial College London School of Medicine, London, UK

4 Fortius Clinic, London, UK
PEEK Polyether-ether-ketone

PMMA Polymethyl methacrylate

\section{Introduction}

Meniscal injury significantly affects quality of life [32], and meniscal surgery is one of the most common orthopaedic surgical interventions worldwide $[1,7,18,32]$, with 1 million meniscal surgeries occurring annually in the United States alone [21]. Only approximately $15-35 \%$ of meniscus tears are repairable $[8,33]$. When meniscus repair is not possible, the current standard of care is meniscectomy for symptomatic tears having failed non-surgical treatment. Although meniscectomy may alleviate symptoms in the 
short term, it increases the risk of the onset of osteoarthritis [7, 18, 21, 23, 27-29]. Other treatment options, including meniscal allograft transplants $[22,35]$ and partial replacement scaffolds [21, 23, 30, 34, 42], have limited success in long-term function and survivorship [14, 15, 41]. Novel total meniscus replacement devices have been proposed to fill this treatment gap [19, 26, 37].

Adequate fixation is crucial for the success and functionality of total meniscus replacements. Total meniscus replacements currently in development have used sutures for fixation in large animal models. Sutures connected to the anterior and posterior horns of the implant were passed through transosseous tunnels in the tibia and tied distally with a knot or endobutton ${ }^{\mathrm{TM}}[4,16,37,38]$. However, in vivo data reported implant extrusion and fixation ruptures with such fixation systems. One total meniscus prototype utilised a novel screw-type fixation method in transosseous tunnels for large animal studies [43] but proceeded with a free-floating device requiring an intact meniscal rim for clinical trials [19].

Interference screws inserted between a graft and bone in transosseous tunnels are well established for fixation of anterior cruciate ligament (ACL) grafts [5, 12, 31], and have also been used for the fixation of a resorbable meniscus replacement scaffold $[20,25,26]$.

The aim of this study was to characterise the interference screw fixation system developed for a novel fibre-matrixreinforced synthetic total meniscus replacement in an ovine cadaveric model. It was hypothesized that the interference screw fixation would provide equivalent mechanics to native meniscus attachments in response to ultimate tensile load and dynamic load.

\section{Materials and methods}

Textile straps with a rectangular cross-section, composed of Dyneema Purity ${ }^{\circledR}$ fibres (DSM Biomedical, Geleen, NL) and identical in material and structure to the textile attachments of the novel total meniscus replacement, were manufactured for this study. Tensile and cyclic creep testing on textile straps determined the peak failure load, peak strain, and creep strain. Fixation testing evaluated slippage following cyclic loading and ultimate failure load of the straps when fixed in ovine tibiae with polyether-ether-ketone (PEEK) or titanium alloy interference screw. Research Ethics Committee approval was not required for this study.

\section{Tensile testing}

Textile straps $(n=15)$ were tested for peak failure load using a screw-driven materials testing machine (5565, Instron Ltd, High Wycombe, UK; tensile failure load accuracy $\pm 4 \mathrm{~N}$, position accuracy $\pm 0.02 \mathrm{~mm}$ ). The straps had a cross-section of $4.4 \pm 0.1 \mathrm{~mm}$ by $1.5 \pm 0.1 \mathrm{~mm}$ and a length of $300 \mathrm{~mm}$. The ends of the strap were wrapped around $10 \mathrm{~mm}$-diameter pins and gripped between Instron crosshead clamps with $100 \pm 5 \mathrm{~mm}$ gauge length as described by ASTM-D5035 [3]. Markings were made across the strap at the inner edge of both clamp jaws to detect any movement during testing, indicating slippage of the strap at the jaws. The straps were loaded in tension at a rate of $100 \mathrm{~mm} / \mathrm{min}$ until failure [13, $36,40]$. During preliminary testing, it was noted that failure occurred gradually over multiple load peaks as different strands in the fibre straps broke with increasing elongation. Given this, the peak failure load and peak elongation were specified as the maximum recorded load of the first peak, indicating the primary point of failure. The peak strain (\%) was determined from the peak elongation and gauge length of each individual strap. Structural stiffness $(\mathrm{N} / \mathrm{mm})$ was calculated as the slope of the linear region of the force-elongation curves using linear regression [36, 40].

\section{Creep testing}

Textile straps $(n=5)$ were tested for creep using a servohydraulic materials testing machine (8874, Instron Ltd, High Wycombe, UK). The straps had a cross-section of $4.5 \pm 0.1 \mathrm{~mm}$ by $1.6 \pm 0.1 \mathrm{~mm}$ and a length of $300 \mathrm{~mm}$. The ends of the straps were wrapped around $10 \mathrm{~mm}$-diameter pins and gripped between Instron crosshead clamps with $90 \pm 4 \mathrm{~mm}$ gauge length [3]. Markings were made across the strap at the clamp jaws to detect any movement during testing, indicating slippage of the strap at the jaws. Following 20 preconditioning cycles from 0 to $50 \mathrm{~N}$, the load was increased to $145 \mathrm{~N}$ and 1000 cycles between 70 and $220 \mathrm{~N}$ were applied at $1 \mathrm{~Hz}$. This has been used previously to represent the loads experienced by the ACL during normal walking $[5,9,12,17,22,31]$. Creep strain was determined at the maximum and minimum load points from the elongation data and gauge length of each individual strap.

\section{Fixation testing}

The interference screw fixation of textile straps in anterior and posterior transosseous tunnels was tested. The anterior and posterior transosseous tunnels replicated the preferred surgical procedure for in vivo ovine studies. At the anterior tunnel, PEEK (BIOSURE PK, Smith \& Nephew, UK) and titanium alloy Ti6Al4Va interference screw (QUICKSTART, Innovate Orthopaedics, UK) were tested. At the posterior tunnel, single titanium interference screw fixation showed excessive slippage during early cyclic testing, so double fixation was used. Posterior tunnel fixation was implemented using solely titanium interference screw 
given PEEK screws could not be inserted successfully without blunting.

Fresh-frozen tibias from North of England Mule ewes aged $>2$ years and weighing $56-68 \mathrm{~kg}$, with all soft tissues removed, were defrosted immediately prior to testing and kept moist throughout the test. Each tibia was fixed in a stainless-steel pot using three screws and then secured with polymethyl methacrylate (PMMA). In each tibia, an anterior and two posterior $4.5 \mathrm{~mm}$ tunnels were prepared using a drill guide. The $20 \mathrm{~mm}$-long anterior tunnel was drilled from the antero-lateral (AL) aspect of the tibial metaphysis up to the plateau at the anterior root attachment of the medial meniscus. The $40 \mathrm{~mm}$-long primary posterior tunnel was drilled from the $\mathrm{AL}$ aspect of the tibia, further distal to the anterior tunnel, up to the posterior root attachment of the medial meniscus. A second posterior tunnel was drilled transversely across the distal tibia from the AL aspect to the antero-medial (AM) side to provide double fixation at the posterior attachment, and was 15-20 mm long depending on tibial shaft size (Fig. 1a).

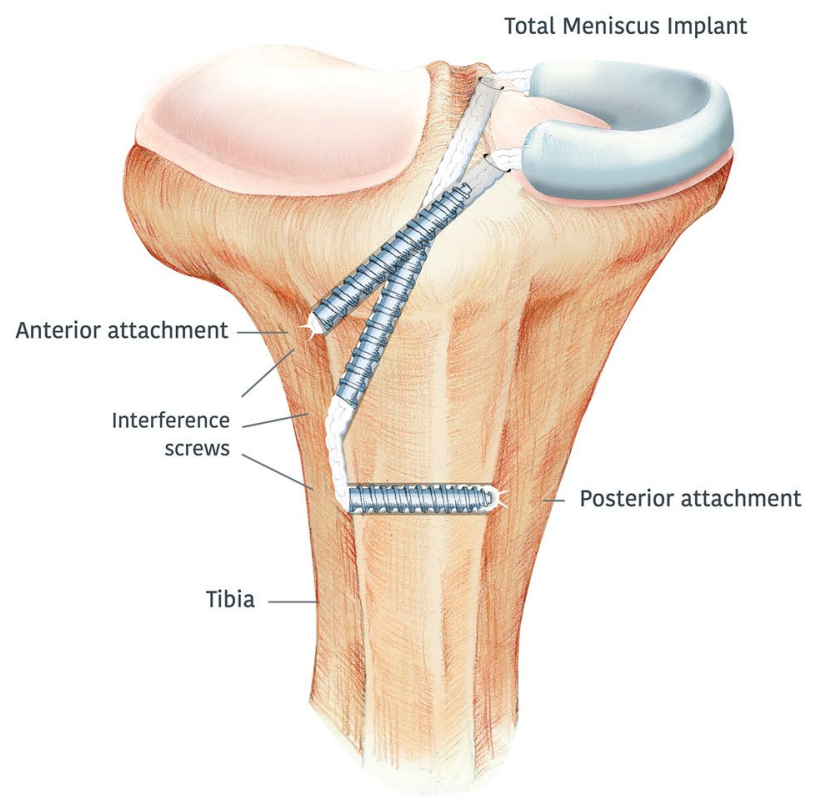

$\mathbf{a}$

Fig. 1 Interference screw fixation of a total ovine medial meniscus replacement. a Anterior-posterior view with representation of the ovine medial meniscus implant fixation using interference screws within tibial bone tunnels. b Fixation testing setup for evaluating tex-
A textile strap was secured at the distal end of each anterior tunnel with a $6 \times 20 \mathrm{~mm}$ titanium $(n=6)$ or PEEK interference screw $(n=5)$. For the posterior tunnel, the strap was passed through the primary posterior tunnel and then through the secondary tunnel, exiting on the AM aspect of the tibia. A $6 \times 25 \mathrm{~mm}$ titanium screw was inserted into the distal end of the primary posterior tunnel and a $6 \times 20 \mathrm{~mm}$ or $6 \times 25 \mathrm{~mm}$ titanium screw, depending on the tunnel length, was inserted into the secondary posterior tunnel $(n=6)$. The interference screw in the second posterior tunnel provided bicortical fixation. All interference screws were inserted from the AL aspect of the tibia.

The tibial pot was inserted into a fixture that was mounted on the test bed of a servohydraulic materials testing machine (model 8874, Instron Ltd, High Wycombe, UK; cyclic creep load accuracy $\pm 1.1 \mathrm{~N}$, position accuracy $\pm 0.2 \mathrm{~mm}$ ) (Fig. 1b). The fixture allowed the tibial tunnel being tested to be aligned to the loading axis $[5,12]$. For the posterior double tunnel, the primary posterior tunnel was aligned to the loading axis. Markings were made across the strap at the clamp jaws to detect any movement during testing,

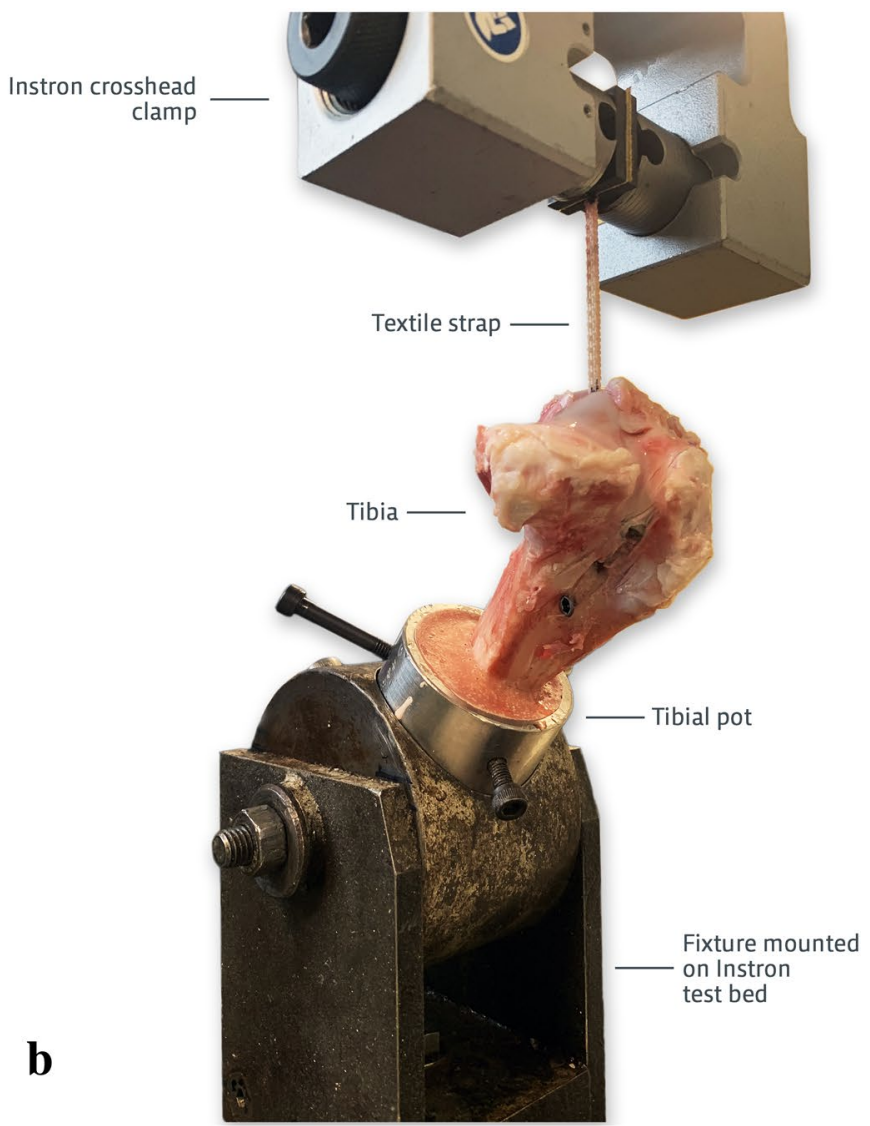

tile strap extension and pull-out load at the bone/interference screw interface in anterior and posterior tunnels. Each bone tunnel was aligned to the tensile loading axis 
indicating slippage of the strap at the jaws. Following 20 preconditioning cycles from 0 to $50 \mathrm{~N}$, the load was increased to $145 \mathrm{~N}$ and 1000 cycles between 70 and $220 \mathrm{~N}$ were applied at $1 \mathrm{~Hz}[5,9,12,17,22,31]$. The maximum extension at each load cycle was recorded, indicating the combined textile strap creep and slippage from the bone/ interference screw interface. A pull-out test was then applied to the strap at $1000 \mathrm{~mm} / \mathrm{min}$ [12], and the maximum force was recorded.

\section{Statistical analysis}

A power analysis using $\mathrm{G}^{*}$ Power v3.1.9.7 [10], based on similar work on the strength of interference screw fixation [5], found that a sample size of six specimens per group would enable identification of significant differences of $75 \mathrm{~N}$ with $95 \%$ probability and $80 \%$ power.

A one-way ANOVA and Tukey's multiple comparisons test was performed to detect significant differences in pullout load and extension between each tested fixation method (PEEK/titanium screw and anterior/posterior tunnel) (Prism Version 8.4.3 for Windows, GraphPad Software, La Jolla California USA). Differences were considered significant at $p<0.05$.

\section{Results}

\section{Tensile testing}

The peak load of the textile straps was $888 \pm 137 \mathrm{~N}$ (mean \pm standard deviation, $n=15$ ), elongation $6.2 \pm 1.4 \mathrm{~mm}$, strain $6.2 \pm 1.3 \%$, and stiffness (slope of the linear region of the force-elongation curve, $R^{2}=0.997$ ) was $242 \pm 33 \mathrm{~N} / \mathrm{mm}$. No slippage of the textile straps was detected at the clamp jaws during testing.

\section{Creep testing}

At the first 70-220 N load cycle, the tensile strain of the textile straps at $220 \mathrm{~N}$ was $0.016 \pm 0.003$ (mean \pm standard deviation, $n=5$ ); this increased to $0.021 \pm 0.004$ after 1000 cycles (Fig. 2). Therefore, the mean creep strain in the straps was 0.005 after 1000 loading cycles. No slippage of the textile straps was detected at the clamp jaws during testing.

\section{Fixation testing}

The extension $(\mathrm{mm})$ and pull-out load $(\mathrm{N})$ for each interference screw fixation type tested are shown in Fig. 3. No textile straps slipped from the clamp jaws or ruptured during testing. During the pull-out test, the main mode of failure in the anterior tunnel was slippage of the textile strap at the fixation interface until it was completely pulled out of the bone. In the posterior double tunnel, pull-out mainly resulted in the fracture of the tibial diaphysis between the two posterior AL tunnel apertures (Fig. 4). Under visual inspection, straps pulled out from the posterior double tunnel were noticeably damaged by the titanium interference screw threads. ANOVA and post hoc analysis detected no significant differences in extension between the three fixation methods (n.s.). The posterior double-tunnel fixation pull-out load was significantly higher than both the PEEK and titanium anterior tunnel fixation methods $(p<0.01)$, with the two anterior tunnel fixations being comparable (n.s.).

\section{Discussion}

The most important findings of this study were that the fixation strength of the novel total meniscus replacement interference screw fixation system was similar to that of human meniscal root attachments, and that the resistance to slipping under cyclic loads was similar to that of well-established
Fig. 2 Cyclic strain of textile straps loaded between 70 and $220 \mathrm{~N}$ for 1000 cycles. Mean strap strain \pm standard deviation against number of cycles $(n=5)$. Average strain and standard deviation at the higher bound of the cyclic load $(220 \mathrm{~N})$ is shown in grey; lower bound $(70 \mathrm{~N})$ is shown in red

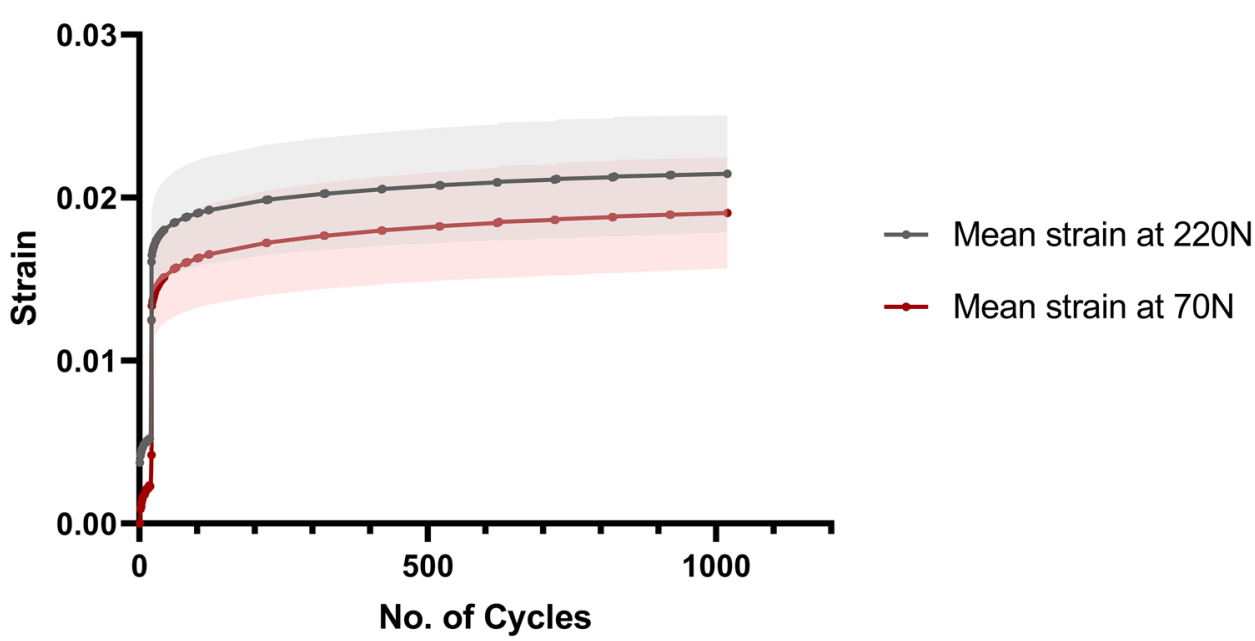




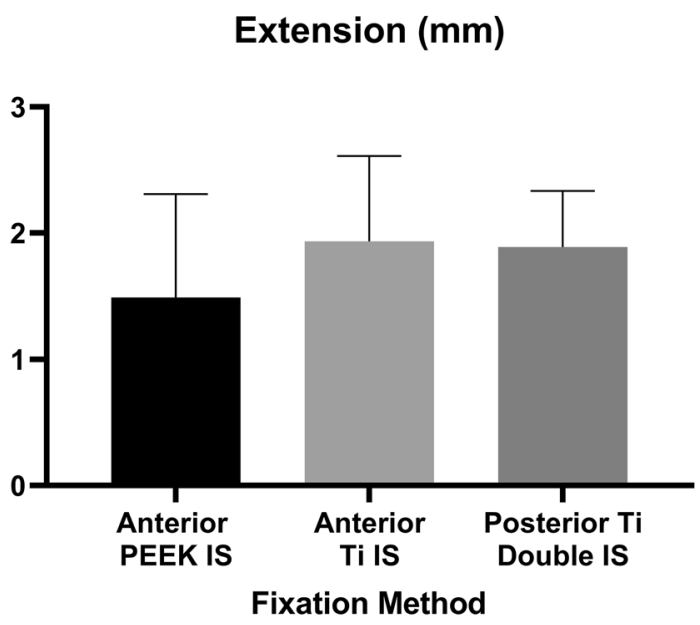

Fig. 3 Interference screw (IS) fixation extension (left) and pull-out load (right). Mean + standard deviation reported for both screw types at the anterior and posterior double tunnels $(n \geq 5)$. Adjusted $p$ values

\section{Pull-out Load (N)}

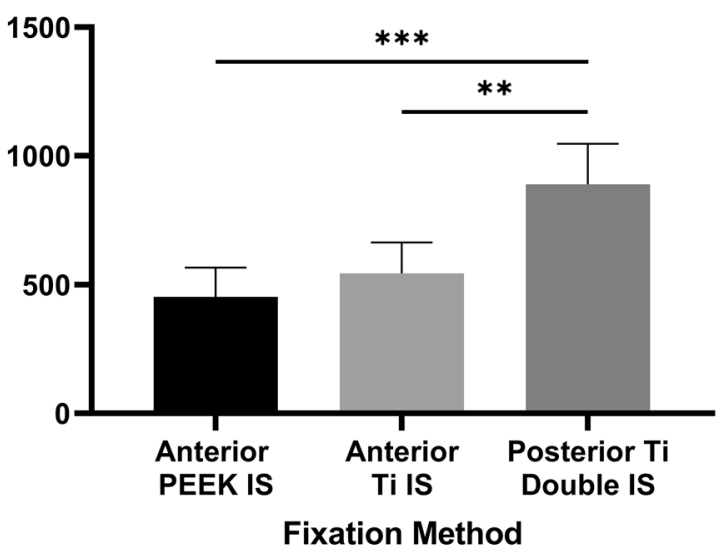

(one-way ANOVA) represent differences between groups (** significant at $p<0.01, * * *$ significant at $p<0.001$ )
Fig. 4 A representative ovine tibia showing bone fracture between the two posterior antero-lateral (AL) tunnel apertures, the main mode of failure of pull-out testing of a textile strap fixed with two titanium interference screws in a posterior double tunnel

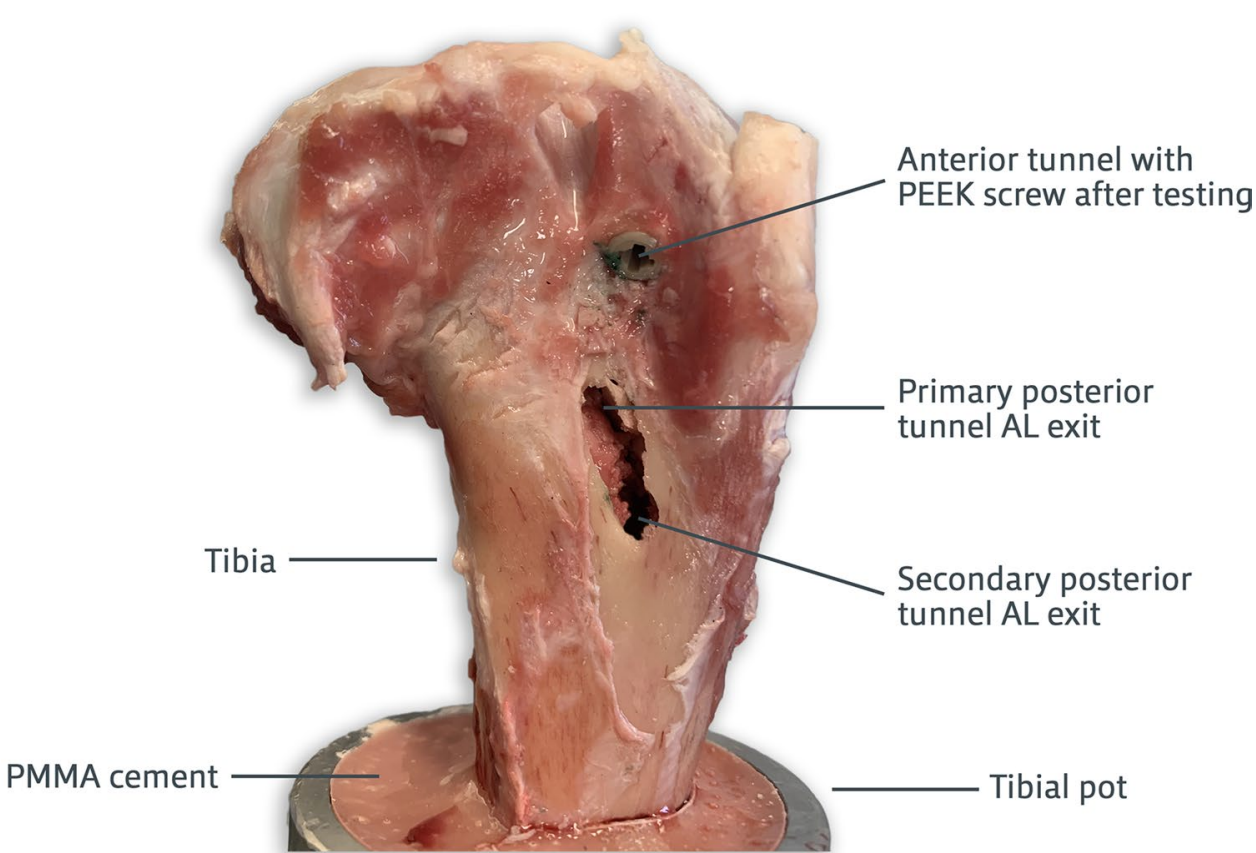

human ACL graft fixation methods, confirming the original hypotheses despite conducting tests in smaller ovine bones. The tensile strength of the double interference screw fixation system was such that during pull-out, fixation failure occurred by tibial bone fracture. These findings support the evaluation of ovine meniscus implants with interference screw fixation in vivo.

Previous studies have characterised the ultimate failure load and stiffness of human meniscus roots $[6,13]$. Patel et al. recorded ultimate tensile load for native human meniscus roots and a resorbable meniscus scaffold attachment with antegrade screw fixation in the anterior tunnel and retrograde fixation in the posterior tunnels [24]. The peak strap failure load and the fixation pull-out load in the present study were comparable to human meniscal root strength reported by Patel et al. (735 N anterior and $549 \mathrm{~N}$ posterior), Hauch et al. $(501 \mathrm{~N})$, and Ellman et al. $(583 \mathrm{~N})[6,13,24]$.

Based on the biomechanics of the natural meniscus, meniscus replacement attachments require a high stiffness to maintain low strains at peak loads, avoiding implant extrusion, and a high tensile strength to prevent root rupture. Due to differences among specimens, it was not possible to compare the stiffness of the textile attachment strap to previous studies [24]. When scaled by sample gauge length, 
the strap stiffness was at least 12 times that recorded for human meniscal roots $[6,13]$. The peak strain of the textile strap was comparable to the lower end of the strain range reported for human meniscus attachments [13]. These data imply a low risk of rupture or meniscus implant loosening when subjected to physiological loading.

Given that minimal cyclic creep strain was exhibited by the textile strap, it follows that the extension measured during fixation testing was primarily due to slippage at the interference screw fixation interface following 1000 cycles. Clinically, excessive slippage could hinder implant performance in relation to distributing the contact pressures of the knee and providing chondroprotection. Slippage results from this study were within the acceptable range for ACL graft reconstruction in studies with similar loading conditions and fixation systems $[2,5,9,11,17,31,39]$.

Interference screw fixation was chosen for this meniscus replacement implant given its high success rate in ACL reconstruction. Additionally, such a fixation system can be used in arthroscopic procedures and is a well-established procedure among orthopaedic surgeons. For a medial meniscus implant, both the anterior and primary posterior tunnel external apertures were located on the antero-lateral aspect of the tibia to minimise disruption to musculature and innervation to mimic in vivo practice, while still maintaining comparable insertion angles to native meniscus roots. Following a pilot study, double fixation was included on the posterior tunnel to reduce slippage to a value comparable to that of the anterior tunnel, so the pull-out load of the posterior double fixation was at least $63 \%$ greater than in the anterior tunnel. The interference screw providing double fixation in the posterior tunnel was inserted from the anterolateral aspect of the tibia, rather than the antero-medial aspect, to avoid introducing additional incisions on the tibia and also to ensure that the interference screw was embedded in tissue, reducing the possibility of infection during in vivo studies. Furthermore, the fixation testing setup was such that the loading direction of the Instron machine was co-axial with the transosseous tunnel being tested, representing the worst-case scenario. The data suggest that surgical techniques similar to ligament reconstruction may be used for the fixation of meniscal prostheses potentially allowing for faster clinical adoption - the interference screws securing textile straps within the ovine tibial bone tunnels gave similar fixation performance to data published for human ACL reconstructions.

This study has limitations; first, tests were performed on ovine cadaveric tibias and at time point zero, which fail to simulate in vivo conditions, including biological healing and tissue regeneration following the surgical procedure. The possibility of ingrowth into the textile attachments of the novel meniscus replacement implant could further increase the fixation strength and minimise slippage over time. Second, only titanium interference screws were investigated in the posterior tunnel, given that PEEK screws were damaged during insertion at the posterior tunnel. Finally, bone density, which could influence interference screw fixation strength, was not investigated as cadaveric tibias tested were from the same sheep breed and weight range.

\section{Conclusions}

This study found that the novel textile attachment-interference screw fixation system has equivalent ultimate failure load and slippage to native meniscus roots and well-established ACL graft fixation systems, respectively, confirming the hypothesis. These clinically relevant findings support progression to novel fibre-matrix-reinforced total meniscus implant testing in ovine stifles in vivo and will also provide a baseline for future development of human meniscus replacements, in relation to attachment design and fixation methods.

Acknowledgements The authors would like to thank Orthonika Ltd. and Arthritis Research UK for funding this work and providing testing materials and surgical equipment for this study.

Author contributions MKB made substantial contributions to study design, acquisition of data, statistical analysis, and interpretation of data. MKB drafted the manuscript. EP made important contributions to study design, acquisition of data, and statistical analysis. KKA participated in the design of the study and test protocols. SN made contributions to the surgical design of the fixation system tested. MAA conceived of the study and participated in its design and coordination. DD participated in the design of the study and revised the manuscript critically for important intellectual content. AW made contributions to the surgical design of the fixation system and provided critical input on the surgical procedure. AAA made substantial contributions to study design and conception, managed the work, and revised the manuscript critically for important intellectual content. All authors read and approved the final manuscript. MKB and AAA agree to be accountable for all aspects of the work in ensuring that questions related to the accuracy or integrity of any part of the work are appropriately investigated and resolved.

\section{Declarations}

Conflict of interest Ms Bartolo, Dr Provaggi, and Dr Accardi are employees of and own stock or stock options in Orthonika Ltd. Prof Amis, Prof Dini, and Mr Williams own stock or stock options in Orthonika Ltd. Mr Newman is a paid consultant of Orthonika Ltd. Mr Williams is a board member and part-owner in Innovate Orthopaedics.

Funding This work was supported by a grant paid to Imperial College London from Orthonika Ltd. The Instron materials testing machines were provided by a grant from Arthritis Research UK.

Ethical approval Not required for this study.

Informed consent Not required for this study. 
Open Access This article is licensed under a Creative Commons Attribution 4.0 International License, which permits use, sharing, adaptation, distribution and reproduction in any medium or format, as long as you give appropriate credit to the original author(s) and the source, provide a link to the Creative Commons licence, and indicate if changes were made. The images or other third party material in this article are included in the article's Creative Commons licence, unless indicated otherwise in a credit line to the material. If material is not included in the article's Creative Commons licence and your intended use is not permitted by statutory regulation or exceeds the permitted use, you will need to obtain permission directly from the copyright holder. To view a copy of this licence, visit http://creativecommons.org/licenses/by/4.0/.

\section{References}

1. Abram SGF, Judge A, Beard DJ, Price AJ (2018) Adverse outcomes after arthroscopic partial meniscectomy: a study of 700000 procedures in the national Hospital Episode Statistics database for England. Lancet 392:2194-2202

2. Aga C, Rasmussen MT, Smith SD, Jansson KS, Laprade RF, Engebretsen L, Wijdicks CA (2013) Biomechanical comparison of interference screws and combination screw and sheath devices for soft tissue anterior cruciate ligament reconstruction on the tibial side. Am J Sports Med 41:841-848

3. ASTM International (2019) D5035-11 (2019) Standard test method for breaking force and elongation of textile fabrics (strip method). ASTM International, West Conshohocken

4. Chiari C, Koller U, Dorotka R, Eder C, Plasenzotti R, Lang S, Ambrosio L, Tognana E, Kon E, Salter D, Nehrer S (2006) A tissue engineering approach to meniscus regeneration in a sheep model. Osteoarthr Cartil 14:1056-1065

5. Coleridge SD, Amis AA (2004) A comparison of five tibial-fixation systems in hamstring-graft anterior cruciate ligament reconstruction. Knee Surg Sports Traumatol Arthrosc 12:391-397

6. Ellman MB, Laprade CM, Smith SD, Rasmussen MT, Engebretsen L, Wijdicks CA, Laprade RF (2014) Structural properties of the meniscal roots. Am J Sports Med 42:1881-1887

7. Englund M, Lohmander LS (2006) Meniscectomy and osteoarthritis: what is the cause and what is the effect? Fut Rheumatol 1:207-215

8. Espejo-Reina A, Aguilera J, Espejo-Reina MJ, Espejo-Reina MP, Espejo-Baena A (2019) One-third of meniscal tears are repairable: an epidemiological study evaluating meniscal tear patterns in stable and unstable knees. Arthroscopy 35:857-863

9. Fabbriciani C, Mulas PD, Ziranu F, Deriu L, Zarelli D, Milano G (2005) Mechanical analysis of fixation methods for anterior cruciate ligament reconstruction with hamstring tendon graft. An experimental study in sheep knees. Knee 12:135-138

10. Faul F, Erdfelder E, Lang A-G, Buchner A (2007) G*Power 3: a flexible statistical power analysis program for the social, behavioral, and biomedical sciences. Behav Res Methods 39:175-191

11. Giurea M, Zorilla P, Amis AA, Aichroth P (1999) Comparative pull-out and cyclic-loading strength tests of anchorage of hamstring tendon grafts in anterior cruciate ligament reconstruction. Am J Sports Med 27:621-625

12. Halewood C, Hirschmann MT, Newman S, Hleihil J, Chaimski G, Amis AA (2011) The fixation strength of a novel ACL softtissue graft fixation device compared with conventional interference screws: a biomechanical study in vitro. Knee Surg Sports Traumatol Arthrosc 19:559-567

13. Hauch KN, Villegas DF, Haut Donahue TL (2010) Geometry, time-dependent and failure properties of human meniscal attachments. J Biomech 43:463-468
14. Haunschild ED, Gilat R, Okoroha K, Cole BJ (2020) Failure of meniscus allograft transplantation. Oper Tech Sports Med 28:150713. https://doi.org/10.1016/j.otsm.2019.150713

15. Hutchinson ID, Moran CJ, Potter HG, Warren RF, Rodeo SA (2013) Restoration of the meniscus: form and function. Am J Sports Med 42:987-998

16. Kelly BT, Robertson W, Potter HG, Deng XH, Turner AS, Lyman S, Warren RF, Rodeo SA (2007) Hydrogel meniscal replacement in the sheep knee: preliminary evaluation of chondroprotective effects. Am J Sports Med 35:43-52

17. Mayr R, Heinrichs CH, Eichinger M, Coppola C, Schmoelz W, Attal R (2015) Biomechanical comparison of 2 anterior cruciate ligament graft preparation techniques for tibial fixation: adjustable-length loop cortical button or interference screw. Am J Sports Med 43:1380-1385

18. McDermott ID, Masouros SD, Amis AA (2008) Biomechanics of the menisci of the knee. Curr Orthop 22:193-201

19. McKeon BP, Zaslav KR, Alfred RH, Alley RM, Edelson RH, Gersoff WK, Greenleaf JE, Kaeding CC (2020) Preliminary results from a US clinical trial of a novel synthetic polymer meniscal implant. Orthop J Sport Med 8:1-10

20. Merriam AR, Patel JM, Culp BM, Gatt CJ, Dunn MG (2015) Successful total meniscus reconstruction using a novel fiberreinforced scaffold. Am J Sports Med 43:2528-2537

21. Murphy CA, Garg AK, Silva-Correia J, Reis RL, Oliveira JM, Collins MN (2019) The meniscus in normal and osteoarthritic tissues: facing the structure property challenges and current treatment trends. Annu Rev Biomed Eng 21:495-521

22. Novaretti JV, Patel NK, Lian J, Vaswani R, de Darren SA, Getgood A, Musahl V (2019) Long-Term survival analysis and outcomes of meniscal allograft transplantation with minimum 10-year follow-up: a systematic review. Arthroscopy 35:659-667

23. Patel H, Skalski MR, Patel DB, White EA, Tomasian A, Gross JS, Vangsness CT, Matcuk GR (2021) Illustrative review of knee meniscal tear patterns, repair and replacement options, and imaging evaluation. Clin Imaging 69:4-16

24. Patel JM, Brzezinski A, Raole DA, Dunn MG, Gatt CJ (2018) Interference screw versus suture endobutton fixation of a fiberreinforced meniscus replacement device in a human cadaveric knee model. Am J Sports Med 46:2133-2141

25. Patel JM, Ghodbane SA, Brzezinski A, Gatt CJ, Dunn MG (2018) Tissue-engineered total meniscus replacement with a fiberreinforced scaffold in a 2-year ovine model. Am J Sports Med 46:1844-1856

26. Patel JM, Merriam AR, Culp BM, Gatt CJ, Dunn MG (2015) One-year outcomes of total meniscus reconstruction using a novel fiber-reinforced scaffold in an ovine model. Am J Sports Med 44:898-907

27. Roemer FW, Kwoh CK, Hannon MJ, Hunter DJ, Eckstein F, Grago J, Boudreau RM, Englund M, Guermazi A (2017) Partial meniscectomy is associated with increased risk of incident radiographic osteoarthritis and worsening cartilage damage in the following year. Eur Radiol 27:404-413

28. Rongen JJ, Rovers MM, van Tienen TG, Buma P, Hannink G (2017) Increased risk for knee replacement surgery after arthroscopic surgery for degenerative meniscal tears: a multi-center longitudinal observational study using data from the osteoarthritis initiative. Osteoarthr Cartil Elsevier Ltd 25:23-29

29. Roos H, Laurén M, Adalberth T, Roos EM, Jonsson K, Lohmander LS (1998) Knee osteoarthritis after meniscectomy: prevalence of radiographic changes after twenty-one years, compared with matched controls. Arthritis Rheum 41:687-693

30. Stone KR, Steadman JR, Rodkey WG, Li ST (1997) Regeneration of meniscal cartilage with use of a collagen scaffold. Analysis of preliminary data. J Bone Jt Surg Am 79:1770-1777 
31. Sun T, Zhang H (2021) Biomechanical comparison of a novel tibial fixation technique versus interference screw fixation for ACL reconstruction using soft tissue grafts. Orthop J Sport Med 9:232596712110285

32. Thorlund JB, Englund M, Christensen R, Nissen N, Pihl K, Jørgensen U, Schjerning J, Lohmander LS (2017) Patient reported outcomes in patients undergoing arthroscopic partial meniscectomy for traumatic or degenerative meniscal tears: comparative prospective cohort study. Brit Med J 356:1-9

33. Tudor F, McDermott ID, Myers P (2014) Meniscal repair: a review of current practice. Orthop Trauma 28:88-96

34. Verdonk R, Verdonk P, Huysse W, Forsyth R, Heinrichs EL (2011) Tissue ingrowth after implantation of a novel, biodegradable polyurethane scaffold for treatment of partial meniscal lesions. Am J Sports Med 39:774-782

35. Verdonk R, Volpi P, Verdonk P, Van Der BH, Van LM, Almqvist KF, Vander ES, Prospero E, Quaglia A (2013) Indications and limits of meniscal allografts. Injury 44:S21-S27

36. Villegas DF, Maes JA, Magee SD, Haut Donahue TL (2007) Failure properties and strain distribution analysis of meniscal attachments. J Biomech 40:2655-2662

37. Vrancken ACT, Hannink G, Madej W, Verdonschot N, Van Tienen TG, Buma P (2017) In vivo performance of a novel, anatomically shaped, total meniscal prosthesis made of polycarbonate urethane: a 12-month evaluation in goats. Am J Sports Med 45:1-11

38. Vrancken ACT, Madej W, Hannink G, Verdonschot N, Van Tienen TG, Buma P (2015) Short term evaluation of an anatomically shaped polycarbonate urethane total meniscus replacement in a goat model. PLoS ONE 10:1-16
39. Walsh MP, Wijdicks CA, Parker JB, Hapa O, LaPrade RF (2009) A comparison between a retrograde interference screw, suture button, and combined fixation on the tibial side in an all-inside anterior cruciate ligament reconstruction: a biomechanical study in a porcine model. Am J Sports Med 37:160-167

40. Warnecke D, Stein S, Haffner-Luntzer M, de Roy L, Skaer N, Walker R, Kessler O, Ignatius A, Dürselen L (2018) Biomechanical, structural and biological characterisation of a new silk fibroin scaffold for meniscal repair. J Mech Behav Biomed Mater 86:314-324

41. Winkler PW, Rothrauff BB, Buerba RA, Shah N, Zaffagnini S, Alexander P, Musahl V (2020) Meniscal substitution, a developing and long-awaited demand. J Exp Orthop 7:55

42. Zaffagnini S, Fink C, Grassi A, Marcheggiani Muccioli GM, Marcacci M (2015) Meniscal implants: indications and outcomes. Arthroskopie 28:1-5

43. Zur G, Linder-Ganz E, Elsner JJ, Shani J, Brenner O, Agar G, Hershman EB, Arnoczky SP, Guilak F, Shterling A (2011) Chondroprotective effects of a polycarbonate-urethane meniscal implant: histopathological results in a sheep model. Knee Surg Sports Traumatol Arthrosc 19:255-263

Publisher's Note Springer Nature remains neutral with regard to jurisdictional claims in published maps and institutional affiliations. 